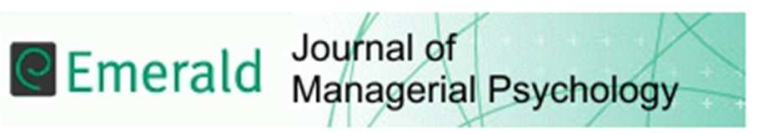

\title{
The role of person-job fit in the relationship between transformational leader and job engagement
}

\begin{tabular}{|r|l|}
\hline Journal: & Journal of Managerial Psychology \\
\hline Manuscript ID & JMP-05-2016-0144.R2 \\
\hline Manuscript Type: & Research Paper \\
\hline Keywords: & person-environment fit, Transformational leadership, work engagement \\
\hline \multicolumn{2}{|c}{} \\
\hline
\end{tabular}

SCHOLARONE ${ }^{\text {In }}$

Manuscripts 


\title{
The role of person-job fit in the relationship between transformational leader and job engagement
}

\begin{abstract}
Purpose - This paper explores the relationship between transformational leadership and employees' work engagement based on fit theory. The paper reports an investigation into the way in which employees' perceptions of transformational leadership and person-job fit affect their work engagement.

Design/methodology/approach - To test our hypotheses, we performed structure equation modelling with maximum likelihood estimation on Mplus with bootstrapping proposed by Hayes (2009) with data from 691 full-time employees in China.
\end{abstract}

Findings - The results indicate that transformational leadership has as significant influence on employees' work engagement as person-job fit in China. Moreover, employees' perception of person-job fit is found to partially mediate the relationship between transformational leadership and employees' work engagement.

Research limitations/implications - There is a possible bias arising from the use of cross-sectional data. However, a number of methods were implemented to minimise it, including survey design and data analysis.

Practical implications - The paper proposes a number of practical implications for policy makers, HR managers and transformational leaders relating to issues associated with improving levels of employee engagement.

Originality/value - The study contributes to developing leadership and engagement theory by examining a previously unexplored mediator - person-job fit - in a neglected cultural setting. This study promises to open new research avenues in this area.

Key Words: Transformational leadership, work engagement, person-job fit, China

Paper type: Research paper 
Within the literature on contemporary human resource management and organizational behavior, transformational leadership (Bass and Avolio, 1994) is a topic that has attracted a high level of attention from scholars and practitioners (Banks et al., 2016; Judge and Piccolo, 2004). It is described as a motivational process through which leaders' behavior affects the attitudes and behavior of their followers (Dvir et al., 2002; Hammond et al., 2015; Michaelis et al., 2010). Empirical studies have repeatedly confirmed the importance of transformational leadership in predicting followers' organisational citizenship behaviour (OCB) (Zacher and Jimmieson, 2013), self-esteem (Matzler et al. 2015), innovation implementation behavior (Michaelis et al., 2010), shared values (Gillespie and Mann, 2006), selfefficacy (Walumbwa et al., 2008), optimism (Xanthopoulou et al., 2007), and task performance (Brouer et al., 2016; Ghadi et al., 2013). However, a complete understanding of transformational leadership and its operating mechanisms remains unclear (Henker et al., 2015). Indeed, Avolio et al. (2004) suggested that the impact of transformational leadership on individual outcomes requires further investigation.

Several scholars such as Bakker et al. (2011) suggest considering whether the level of followers' work engagement can be enhanced by transformational leaders changing followers' perceptions of the working environment. The study provides contributions to the literature through responding to calls to explain the mechanisms by which transformational leaders exert influence on followers' work attitudes and behaviors and, in particular, by exploring this within different cultural settings (Avolio et al., 2004). Furthermore, the generalizability of the construct of transformational leadership in different cultural settings has been the subject of much 
debate as it was developed in a Western cultural context (Spreitzer et al., 2005). This premise has recently attracted the attention of researchers in Asia, particularly China (Li et al., 2015). Therefore, this study is designed to investigate empirically the relationship between transformational leadership and employee engagement through the examination of the mediating effects of followers' perceptions of person-job fit within a Chinese context.

According to Hofstede's four cultural dimensions, China is high in power distance and collectivism (Pheng and Yuquan, 2002). This indicates cultural sensitivity to hierarchy and discipline, Chinese employees are sometimes forced to follow instructions given by their supervisors strictly and are not allowed to perform the job in their own way. This explains why autocratic and moral leadership are traditionally the two most popular types of leadership behaviors in China (Farh and Cheng, 2000). However, with the influence of globalization, leadership styles in China are also changing. This study contributes to the current understanding of the impact of transformational leadership in China.

\section{Theoretical Background and Hypothesis Development}

\section{Fit theory}

Person-environment fit describes the match between people and certain types of organizational environments (Bretz and Judge 1994). We refer it as fit theory. Fit theory has attracted great attention from researchers and practitioners in understanding employees' attitudes and behaviors (Chuang and Sackett, 2005). Fit theory has been conceptualized into two different types: (1) supplementary fit individuals and their surroundings possess similar characteristics; and (2) 
complementary fit - individuals and their surroundings possess different characteristics but are needed by each other to make whole or add to what is missing (Boon et al., 2011; Kristof, 1996). Person-job fit is conceptualized as a complementary fit (Edwards 1991; Kristof-Brown et al. 2005; Lauver and KristofBrown 2001). It is the focus of this study because it investigates whether it mediates the relationship between transformational leadership and followers' work engagement. Person-job fit is defined as the match between the abilities of the person and the demands of a job, or the needs, or desires of a person and what is provided by a job (Edwards 1991), which corresponds with complementary fit (Boon et al., 2011).

Applying fit theory, particularly with a focus on person-job fit, this study fills the gap in the existing transformational leadership literature in terms of understanding the mechanisms through which transformational leadership impacts employees' work engagement. In response to calls made by previous scholars, as well as to fill the gap in the existing transformational leadership literature, this study aims to clarify the underlying engagement mechanisms by employing the construct of person-job fit in fit theory. Thus, further exploration of how transformational leadership impacts on the role and on employees' perceptions of their jobs and organizations and their related work engagement via a mediating role of person-job fit would appear to be warranted. It enhances our understanding of the nexus between transformational leadership and individual outcomes by examining person-job fit as a previously unexplored mediator (Yukl, 2010). 


\section{Work engagement}

The literature presents a diverse range of definitions of work engagement. A commonly agreed and often-cited definition is that proposed by Schaufeli et al. (2002): “a positive, fulfilling, work-related state of mind that is characterised by vigour, dedication, and absorption" (p.74). Vigour refers to higher levels of energy and psychological resilience while working. Dedication is characterised by a sense of motivation, enthusiasm, pride and challenge. Absorption means that an individual is completely concentrated on, and averse to stopping, their work. These three components are also referred to as: physical, emotional and cognitive (May et al., 2004). Despite the fact that work engagement is a well-developed research area in the Western contexts because of its importance in organisational psychology (May et al., 2014), it has received modest attention in an Eastern one (Wang et al., 2013).

\section{Transformational leadership and work engagement}

Discussions of transformational leadership and work engagement are mainly centred on their positive relationship (Salanova et al., 2011). In spite of linking transformational leadership with followers' attitudes and behaviour, there is less empirical evidence exploring how employees' psychological states are affected by transformational leaders (Avolio et al., 2009). Ghadi et al. (2013) have examined the direct relationship between transformational leadership and employee work engagement. As shown in Song et al. (2012), the two constructs have a strong connection. According to Raja (2012), when all dimensions of transformational leadership, namely idealised influence, inspirational motivation, intellectual stimulation and individual consideration (Bass, 1985) are demonstrated together, 
followers' work engagement tends to be higher. Breevaart et al. (2014) and Tims et al. (2011) asserted that transformational leaders increase the level of employees' work engagement on a daily basis. Moreover, Zhu et al. (2009) added that transformational leadership has an even more positive effect on follower work engagement when follower characteristics are more positive, such as being creative, innovative, proactive, taking an initiative, and having a learning orientation.

Scholars and practitioners have focused on exploring how transformational leadership predicts employees' work engagement and have tried to explain the underlying mechanism. Job-related resources contribute to the transformational leadership - work engagement linkage for two main reasons. First, job-related resources involve opportunities in terms of development, empowerment, variable tasks, regular feedback and supportive work environment (Bakker and Demerouti, 2007). Transformational leadership has more impact on OCB, including work engagement, through core job characteristics (Piccolo and Colquitt, 2006). Bakker et al. (2011) propose that leadership - especially transformational leadership can positively influence employees' work engagement through increasing meaningfulness in work. Second, employees who receive support and development opportunities from their supervisors are more likely to engage with their work (Tims et al., 2011). Transformational leaders, thus, can enhance employees' feelings of energy, motivation and involvement in work by consistently supporting and developing them (Shamir et al., 1993).

Studies on transformational leadership have been primarily undertaken within a Western context; thus, the application of experiences from the West to other regions 
needs further consideration and discussion (Walumbwa and Lawler, 2003). There is still limited research conducted in Eastern contexts in terms of testing transformational leadership theory and its relationship to employee outcomes. Among them, Walumbwa and Lawler (2003) supported the effectiveness of the impact of transformational leadership on job satisfaction, organizational commitment and turnover intention in collectivistic cultures. Based on existing evidence, transformational leadership is likely to have a significant impact on work engagement, particularly in the context of Eastern cultures like China. Therefore, we propose our first hypothesis:

Hypothesis 1: Transformational leadership is positively related to employees' work engagement.

\section{A missing link between transformational leadership and work engagement \\ Transformational leadership and person-job fit}

The association between transformational leadership and person-job fit can also be explained by leaders' ability to manage employees' needs. When employees are considered individually, they tend to be motivated to acquire further job skills (Sosik et al., 2004). In his original work on leadership, Bass (1985) suggested that transformational leaders raise employees' needs from lower levels (i.e. physiology and safety) to higher levels (i.e. esteem and self-actualisation) in terms of Maslow's hierarchy of needs. To be specific, it is proposed that transformational leaders deploy approaches such as inspirational motivation to influence employees' attitudes towards their jobs (Purvanova et al., 2006), and increase meaning in work (Arnold et al., 2007), as well as linking the job to a greater purpose (Shamir et al., 1993). Therefore, 
it is reasonable to assume that transformational leaders increase employees' perceived person-job fit. Based on the above arguments, we hypothesise:

Hypothesis 2: Transformational leadership is positively associated with employees' perceptions of person-job fit.

\section{Person-job fit and work engagement}

The relationship between fit perception and work engagement is generally explained by Lewin's Field Theory that "to understand or to predict behaviour, the person and his environment have to be considered as one constellation of interdependent factors" (Lewin, 1952:239). According to this, positive behaviors, such as engagement, are encountered when employees hold a positive perception of their working environment. Subsequently, Maslach and Leiter (1997) empirically corroborated that person-environment fit leads to lower burnout levels and greater work engagement. This included both supplementary and complementary fit. However, all of the existing research on the specific influence of person-job fit on work engagement is limited. Though Maden-Eyiusta (2016) did not test the direct relationship between person-job fit and work engagement, she tested the demands-supplies relationships (demand-abilities fit and needs-supplies fit as complementary fit (Kristof, 1996)) as moderators of job resources and work engagement. Laschinger and Finegan (2005) seem to be the first to link person-job fit with work engagement. They explored the empowerment process in six stages of employees' work life and pointed out that employees reported higher levels of job control (such as autonomy) when they were empowered, which indicated a fit between their expectations and the actual situation 
of their work; this results in work engagement. Building on this discussion, we hypothesize that:

Hypothesis 3: Employees' perceptions of person-job fit are positively related to their work engagement.

\section{Mediating roles of perceived person-job fit}

In summary, the above discussion explains the direct or indirect relationships between: (1) transformational leadership and work engagement; (2) transformational leadership and perceived person-job fit; (3) perceived person-job fit and work engagement. We suggest that it is reasonable to propose that transformational leadership influences employees' perceptions of person-job fit, which in turn has effect on work engagement. That is, transformational leaders are able to increase the fit between employees and their job via value/goal/characteristics complement, which will ultimately enhance employees' work engagement. According to Baron and Kenny (1986), a mediating model is established whereby the relationship between the predictor and outcome variable can be clarified by the third variable. Hence, our last hypothesis is proposed relating to testing the mediating effects of perceived personjob fit on the transformational leadership-work engagement linkage.

Hypothesis 4: Perceived person-job fit of employees mediates the relationship between transformational leadership and work engagement of employees.

\section{Methods}

\section{Sample and procedures}

A sample of 750 full-time employees in China - who were currently working with a direct supervisor (leader) - was selected by nonprobability sampling techniques in 
two steps. Step one involved using personal contacts; we contacted 50 employers from different organizations that varied in regions and sectors in China. According to their positions and the size of their organization, those initial contacts were asked to invite their employees/colleagues to participate in the survey. Later on, email addresses of those potential participants were provided to the researchers along with consent to send out questionnaires to them. Step two involved sending out a total of 750 emails, including the 50 initial contacts. The email explained the purpose of the research and contained a hyperlink to the online survey. Instructions for completing the survey were also included in that e-mail. 691 valid questionnaires were received. The high response rate $(92 \%)$ is common in studies in China due to the strong influence of social relationships in that country (Chan et al., 2002).

Within the sample, $45.7 \%$ of participants were male and $54.3 \%$ female. Male was coded 1, and female 2. Their ages ranged from 18 years to 62 years, with an average of 33 years, and a standard deviation of 8.9 years. Respondents with bachelor degrees accounted for more than half of the sample (54.9\%). Higher educational levels such as Master degrees and PhDs accounted for 19\% and 1.4\%, respectively. $\mathrm{PhD}$ was coded 1, Master 2, degree 3, diploma certificate 4, and high school or below was coded 5. Front line staff accounted for the highest proportion of participants (46.1\%), followed by line managers $(31.2 \%)$, middle managers $(17 \%)$, and senior managers (5.7\%). Senior manager was coded 1, middle manager 2, line manager 3, and frontline staff 4 . The shortest length of work experience was two months, and the longest 42 years, with an average of 10.12 years, and a standard deviation of 9.5 years. Questionnaires were distributed without any selection criterion relating to 
business sector. In practice, $11.5 \%$ of participants worked as civil servants, $30.6 \%$ worked in state-owned organizations, $37.5 \%$ were from private companies, $17 \%$ were from joint venture enterprises, and $4.3 \%$ were from non-profit organizations. Public sector was coded 1, state-owned companies were coded 2 , private sector 3 , jointventure 4, and non-profit 5.

\section{Measures}

The model presented above has two independent variables, one dependent variable (DV), and additional control variables (age, gender, qualifications, and position). Dependent and independent variables were all measured using a Likert scale ('strongly disagree', 'disagree', 'neutral', 'agree', and 'strongly agree'). In addition, three questionnaire translation techniques were applied, including back-translation, committee approach and pre-test procedure (Brislin, 1976) to prevent any methodological problems relating to translation from English to Chinese and vice versa (Sperber et al., 1994).

Work engagement was measured using the Utrecht Work Engagement Scale (UWES) developed by Schaufeli et al. (2002). The scale consists of nine items that indicate the three characteristics that this study has used to define work engagement: vigour, dedication, and absorption. The reliability for this scale in this study is 0.96 . The CFA results show good fit with $X^{2}=150.96$; df $=24$; CFI $=.98$; TLI $=.97$, $\operatorname{RMSEA}=.087$.

Transformational leadership was measured utilising a 20-item scale adopted from Avolio and Bass (2004)'s latest version of the Multifactor Leadership Questionnaire (MLQ-5X). Permission to use the measure was granted. The 
Cronbach's alpha for this scale is 0.97 . The CFA results show good fit with $X^{2}=$ 400.87; df $=165 ; \mathrm{CFI}=.97 ; \mathrm{TLI}=.97, \mathrm{RMSEA}=.045$.

Perceived P-J fit was tested by six items from Cable and DeRue (2002). The Cronbach's alpha for this scale is 0.90 . The CFA results show good fit with $X^{2}=$ $15.50 ; \mathrm{df}=8 ; \mathrm{CFI}=.99 ; \mathrm{TLI}=.99, \mathrm{RMSEA}=.037$.

\section{Validity and Reliability}

As independent and dependent variables were collected from a single respondent and with similar methods, common method bias may lead to inflated estimates of the relationships (Podsakoff and Organ 1986). Thus, we strictly followed procedural and statistical remedies suggested by researchers to address this problem (Podsakoff et al., 2012). We minimized the bias via procedural remedies such as anonymous respondents, dependent variable was put in front of independent variables in the survey. We also used Harman's one-factor test to examine the potential presence of bias in the data. Common method variance is signposted by the emergence of either a single factor or a general factor that explains a majority of the variance (Podsakoff et al. 2003). In our sample no single factor explained the majority of the variance.

In addition, as suggested by Simmering et al. (2016), we employed CFA tests to eliminate the problem of common method variance of this study as stated in the measures. Table 2 presents again the results of CFA of dependent and independent variables, showing acceptable model fit for transformational leadership, work engagement, and person-job fit with CFI, TLI, and RMSEA are close to the permitted ranges (Hu and Bentler, 1999). 
Finally, we calculated the variance inflation factors (VIFs) to assess the possibility of multicollinearity. The results showed that all VIFs were below 3.0. Since a VIF value of greater than 10 would indicate that multicollinearity poses a serious problem (Hair et al., 2010), we concluded that multicollinearity is not a serious problem in this analysis. Based on the above points, we argue that the validity and reliability of our reflective constructs are established.

\section{Results}

Table 1 presents the correlation matrix and descriptive statistics for the sample. The results show that age, position, and work experience are significantly correlated with work engagement, while gender and qualification show no significant result.

\section{Insert Table 1 here}

Structural equation modelling (SEM) approach permits the modelling of latent constructs and the simultaneous estimation of all hypothesis paths (Byrne, 2012). We tested the conceptual model proposed in this study by using SEM procedures with maximum likelihood estimation and bootstrapping $(1,000)$ proposed by Hayes $(2009)$ on the Mplus package by Muthén and Muthén. We compared the fit among a series of confirmatory factor analysis models to determine the best fit model. According to the suggestions by Hair et al. (2010) regarding the root mean square error of approximation (RMSEA), comparative fit index (CFI), and, standardized root mean square residual (SRMR) our hypothesized model exhibited the best fit $\left(\mathrm{X}^{2}=1299.32\right.$ df $=650 ;$ RMSEA $=.038 ;$ CFI $=.96 ;$ TLI $=.96($ Table 2$)$. 


\section{Hypothesis testing}

Figure 1 presents the standardized estimates for all the path coefficients. These coefficients were employed to ascertain the validity of the hypotheses in this study. According to the analytical results, transformational leaders $(\beta=.57, \mathrm{p}<.00)$ are positively associated with their employees' work engagement. Thus, hypothesis 1 is supported. Hypothesis 2 states that transformational leadership is positively associated with employees' perceptions of person-job fit. The result is significant ( $\beta$ $=.48, \mathrm{p}<.00)$. Thus, hypothesis 2 is supported. Furthermore, hypothesis 3 is also supported on the results show that person-job fit $(\beta=.58, \mathrm{p}<.00)$ is positively associated with work engagement. The bootstrapping analysis reveals that person-job fit $(\beta=.29, \mathrm{p}<.01)$ has a partial mediating role on the relationship between transformational leadership and work engagement. Thus, hypothesis 4 is supported.

\section{Insert Table 2 and Figure 1 here}

\section{Discussion}

Conceptualizing person-job fit as complementary fit, this study provides an insight into the link between transformational leadership and employees' work engagement by examining the mediating roles of person-job fit. Using structural equation modelling with bootstrapping, the results show that all hypotheses are confirmed. Primarily, the results indicate that transformational leadership and employees' work engagement are positively related in the Chinese context, and that their relationship is partially mediated by employees' perceptions of person-job fit. This adds to evidence 
regarding the importance of the influence of transformational leadership on employees' work engagement. The findings provide a number of important theoretical and practical implications that are discussed below.

\section{Theoretical implications}

First, this study confirms the positive relationship between transformational leadership and employee engagement that has been shown in the current literature (Ghadi et al., 2013; Raja, 2012; Salanova et al., 2011; Tims et al., 2011), and the fact that people have less control over their own engagement than they think (Byrne et al., 2017) as their engagement can be influenced by other external factors, like the characteristics of their leaders. This study also contributes empirical evidence demonstrating that the positive relationship between transformational leadership and employee engagement is encountered in non-Western contexts. From the findings it appears that in both Eastern and Western contexts transformational leaders have a significant impact on their employees' level of engagement. Thus, we contribute to the broader call for studies of the efficacy of transformational leadership in nonWestern cultures (Avolio, 2004). Together with the findings by Nguyen et al. (2017), this study adds more evidence of positive impacts of transformation leadership in non-Western cultures.

Second and interestingly, in a culture in which "quanxi" reciprocity (employee's personal relations with managers) can assert a positive impact on employees' work engagement (Hu et al., 2004), this study shows that transformational leadership is as an important factor as person-job fit plays a significant role in employee's work engagement. It develops our understanding of 
employees' work engagement further, indicating that work engagement is not only impacted by complementary fit theory that focuses on employee fit to the job as an antecedent of engagement. The current findings indicate that an employees' work engagement can also be influenced by other external or indirect factors such as their leaders' style.

Third, this study contributes to fit theory by demonstrating that employees' work engagement is positively influenced by their perceptions on person-job fit, which can be increased by transformational leaders. In doing this, the study contributes to the transformational leadership and work engagement literature by responding to calls from several scholars who have suggested future research should focus on exploring the mechanisms between transformational leadership and work engagement via the fit theory (Bakker et al., 2011). Indeed, we have demonstrated that the role of perceived person-job fit is a partial mediator in the relationship. This implies two positive associations; one is transformational leadership to person-job fit, and another is person-job fit to work engagement. The first association addresses the limitation that antecedents of person-job fit were mostly centred at the early stages of the employment cycle, such as employee attraction (Saks and Ashforth, 2002), and job choice decision (Resick et al., 2007). This research contributes to the existing fit literature by exploring additional predictors (Colquitt and Zapata-Phelan, 2007) i.e., transformational leadership in this study, and providing further theoretical considerations as stated above. The second association suggests that the higher the level of employees' person-job fit, the more they are likely to be engaged with their work (Hamid and Yahya 2011). In other words, if employees think that they fit with 
the jobs that they are doing, their work engagement tends to be high. In parallel, having transformational leaders in organizations is also likely to raise the level of employees' engagement. In cases where organizations possess both transformational leadership and high level of employees' perceptions of person-job fit, the impact of transformational leadership on employees' work engagement might slightly reduce compared to the impact of person-job fit on employees' work engagement.

\section{Practical implications}

Our study provides some insights that have practical implications. It is important for organizations, especially those in non-Western contexts such as China, to recognize the benefits that transformational leaders would bring to organizations. They also need to pay attention to employees' perceptions of person-job fit for the benefit of their employees' work engagement. Below are some implications for decision makers and HR managers and practitioners, particularly in the contexts of developing countries and high power distance cultures like China.

This study shows decision makers that fostering transformational leaders should become a strategic approach to the long-term development of organizations. Previous research has shown that behaviors associated with transformational leadership can be developed (Kelloway et al., 2000). It would benefit organizations if they introduce development programmes to build transformational leadership capability amongst their leadership population and embed them in practice through related $\mathrm{HR}$ agendas. 
For HR managers and practitioners, matching employees to specific job requirements appears to warrant further attention in the formulation of $\mathrm{HR}$ policies and practices. First, the hiring decisions should depend not only on applicants' 'quanxi' (in case of cultures like China), knowledge, skills and abilities that meet the requirements of the job, but also on how applicants' preferences can be satisfied by the job and its characteristics Second, with transformational leadership, employees' perceptions of person-job fit can be changed (Chang et al., 2010). HR policies and practices relating to performance appraisal and review could be expanded to include feedback and discussion of perceptions of person-job fit and associated development actions to optimise this. Third, an employee's work engagement can be facilitated through developing a more transformational leadership style and developing an understanding of employees' perceptions of their job in order to ensure that action is taken to optimise person-job fit. In other words, if managers possess transformational leadership style, they can promote their employees' work engagement without much effort. This adds one more reason to develop and/or recruit transformational leaders.

\section{Limitations}

As with any research in this field, limitations are unavoidable. Firstly, all of the variables included in the research were measured using same source self-reported data. Given this, the findings may be subject to issues of common method variance (Podsakoff and Organ 1986). Although we undertook procedures to minimize the phenomenon and tested for its presence, the residual risk remains a limitation in this study. Moreover, the use of convenience and snowball sampling methods, and the 
uneven frequency of demographic variables may limit the generalizability of our findings.

\section{Recommendations for future research}

Future research could expand the proposed framework by including additional variables. Although the current study examined the link between transformational leadership and work engagement via person-job fit theory, other forms of fit, such as person-organization fit person-vocation fit, person-group fit, person-supervisor fit, and value fit, could also have a mediating or moderating effects on the relationships explored (Kristof-Brown et al., 2005). By examining diverse forms of fit together, the understanding of how social interaction between individuals and their environment influences the effectiveness of leadership practices could become clearer and more comprehensive. It might also offer HR practitioners useful information in analysing jobs, selecting applicants, designing training plans and improving policies and procedures, which in turn may help to facilitate engaging employees.

Since this paper is the first to examine the mediating roles of perceived person-job fit in the relationship between transformational leadership and employees' work engagement, future studies are encouraged to test the link in other countries rather than China to compare and contrast findings for theory generalization. Calling from debates of best practices versus best fit (Purcell, 1999), it is suggested that scholars who are interested in localizing global management practices should involve inherent factors such as social regulation and national legislation in the framework.

In addition, limitations in the current paper need to be addressed in future studies. For example, the outcome variable could be assessed by a separate 
respondent, or measures of independent and dependent variables could be taken at different points in time, to avoid common method variance (Podsakoff et al, 2012). Finally, future research employing a longitudinal design would be a valuable way of verifying the causality between variables.

\section{Conclusion}

This study explores an emerging area of interest within the field of studies of the organizational effects of transformational leadership and as such makes contributions to the literature in this field. It differs from previous studies by exploring person-job fit as a mechanism through which transformational leaders impacts employees' work engagement. In addition, it provides a contribution to the cross-cultural leadership literature by employing a large cross-sectional sample drawn from organizations in China. 


\section{References}

Arnold, K. A., Turner, N., Barling, J., Kelloway, E. K. and McKee, M. C. (2007), "Transformational leadership and psychological well-being: the mediating role of meaningful work", Journal of Occupational Health Psychology, Vol. 12, No. 3, pp. 193-203.

Avolio, B. J. and Bass, B. M. (2004) Multifactor Leadership Questionnaire: Manual and Sampler Set, 3rd ed., Menlo Park, CA: Mind Garden.

Avolio, B. J., Walumbwa, F. O. and Weber, T. J. (2009), "Leadership: Current theories, research, and future directions", Annual Review of Psychology, Vol. 60, pp. 421-449.

Avolio, B. J., Zhu, W., Koh, W. and Bhatia, P. (2004), “Transformational leadership and organizational commitment: Mediating role of psychological empowerment and moderating role of structural distance", Journal of Organizational Behavior, Vol. 25, No. 8, pp. 951-968.

Baguley, T. (2012) Serious Atats: A Guide to Advanced Statistics for the Behavioral Sciences. Basingstoke: Palgrave.

Bakker, A. B., Albrecht, S. L. and Leiter, M. P. (2011), "Key questions regarding work engagement", European Journal of Work and Organizational Psychology, Vpl. 20, No. 1, pp. 4-28.

Bakker, A. B. and Demerouti, E. (2007), "The Job Demands-Resources model: state of the art”, Journal of Managerial Psychology, Vol. 22, No. 3, pp. 309-328.

Banks, G., McCauley, K. D., Garner, W. and Guler, C. (2016), "A meta-analytic review of authentic and transformational leadership: A test for redundancy", Leadership Quarterly, Vol. 27, No. 4, pp. 634-652.

Baron, R. M. and Kenny, D. A. (1986), “The moderator-mediator variable distinction in social psychological research: conceptual, strategic, and statistical considerations", Journal of Personality and Social Psychology, Vol. 51, No. 6, pp. 1173-1182.

Bass, B. M. (1985) Leadership and Performance Beyond Expectation. New York: Free Press. 
Bass, B. M. (1998), Transformational Leadership: Industrial, Military, and Educational Impact. Mahwah, NJ: Lawrence Erlbaum Associates.

Bass, B. M. (1999), “Two decades of research and development in transformational leadership", European Journal of Work and Organizational Psychology, Vol. 8, No. 1, pp. 9-32.

Bass, B., and Avolio, B. (1994), Improving Organizational Effectiveness, through Transformational Leadership. London: SAGE.

Boon, C., Den Hartog, D. N., Boselie, P. \& Paauwe, J. (2011), “The relationship between perceptions of HR practices and employee outcomes: examining the role of person-organisation and person-job fit", International Journal of Human Resource Management, Vol. 22, No. 1, p138-162.

Breevaart, K., Bakker, A., Hetland, J., Demerouti, E., Olsen, O. K. and Espevik, R. (2014), "Daily transactional and transformational leadership and daily employee engagement", Journal of Occupational and Organizational Psychology, Vol. 87, No. 1, pp. 138-157.

Bretz, R.D., and Judge, T.A. (1994), 'The role of human resource systems in job applicant decision processes,' Journal of Management, Vol. 20, pp. 531-551.

Brislin, R. W. (Ed.). (1976), Translation Applications and Research. New York: Gouldner Press.

Brouer, R. L., Chiu, C-Y, and Wang, L. (2016), "Political skill dimensions and transformational leadership in China", Journal of Managerial Psychology, Vol. 31 Iss: 6, pp.1040 - 1056.

Byrne, B. M. (2012), Structural Equation Modeling with Mplus: Basic Concepts, Applications and Programming. New York: Routledge.

Byrne, Z., Albert, L., Manning, S. and Desir, R. (2017), "Relational models and engagement: an attachment theory perspective", Journal of Managerial psychology, Vol. 32, No. 1, pp. 30-44.

Cable, D. M. and DeRue, D. S. (2002), "The convergent and discriminant validity of subjective fit perceptions", Journal of Applied Psychology, Vol. 87, No. 5, pp. 875-884. 
Chan, R. Y. K., Cheng, L. T. W. and Szeto, R. W. F. (2002), "The dynamics of guanxi and ethics for Chinese executives", Journal of Business Ethics, Vol. 41, pp. 327-336.

Chang, H.-T., Chi, N.-W. and Chuang, A. (2010), "Exploring the moderating roles of perceived person-job fit and person-organization fit on the relationship between training investment and knowledge workers' turnover intentions", Applied Psychology, Vol. 59, No. 4, pp. 566-593.

Colquitt, J. A. and Zapata-phelan, C. P. (2007), “Trends in theory building and theory testing: A five-decade study of the Academy of Management Journal", Academy of Management Journal, Vol. 50, No. 6, pp. 1281-1303.

Dvir, T., Eden, D., Avolio, B. J. and Shamir, B. (2002), "Impact of transformational leadership on follower development and performance: A field experiment", Academy of Management Journal, Vol. 45, No. 4, pp. 735-744.

Edwards, J. R. (1991), Person-Job Fit: A Conceptual Integration, Literature Review, and Methodological Critique. Oxford: John Wiley \& Sons.

Farh, J. L., \& Cheng, B. S. 2000. A cultural analysis of paternalistic leadership in Chinese organizations. In Li, J. T., Tsui, A. S., \& Weldon, E. (Eds.), Management and Organizations in Chinese Context, 84-130. New York: St. Martin's.

Ghadi, M. Y., Fernando, M. and Caputi, P. (2013), "Transformational leadership and work engagement: The mediating effect of meaning in work", Leadership \& Organization Development Journal, Vol. 34, No. 6, pp. 532-550.

Gillespie, N. A. and Mann, L. (2006), "Transformational leadership and shared values: the building blocks of trust", Journal of Managerial Psychology, Vol. 19 No. 6, pp. $588-607$.

Hair, J. F., Black, W. C., Babin, B. J., \& Anderson, R. E. (2010). Multivariate Data Analysis (7th ed.). Englewood Cliffs: Prentice Hall.

Hamid, S. N. A. and Yahya, K. K. (2011), "Relationship between person- job fit and person-organization fit on employees 'work engagement : a study among engineers in semiconductor companies in Malaysia", Annual Conference on Innovations in Business \& Management, London, pp. 1-30. 
Hammond, M., Cleveland, J. N., O'Neill, J. W., Stawski, R. S. and Tate, A. J. , (2015), "Mediators of transformational leadership and the work-family relationship", Journal of Managerial Psychology, Vol. 30 Iss: 4, pp. 454 469.

Hayes, A.F. (2013), Introduction to mediation, moderation, and conditional process analysis: A regression-based approach. New York: Guilford Press.

Hayes, A.F. (2009), "Beyond Baron and Kenny: Statistical mediation analysis in the new millennium”, Communication Monographs, Vol. 76, No. 4, pp. 408-420.

Henker, N., Sonnentag, S. and Unger, D. (2015), “Transformational leadership and employee creativity: The mediating role of promotion focus and creative process engagement", Journal of Business Psychology, Vol. 30, No. 2, pp. 235-247.

Hu, L.T. and Bentler, P.M. (1999), "Cutoff criteria for fit indexes in covariance structure analysis: conventional criteria versus new alternatives”, Structural Equation Modeling: A Multidisciplinary Journal, Vol. 6 No. 1, pp. 1-55.

Hu, Q., Schaufeli, W. B. and Taris, T. W. (2004), "Extending the job demandsresources model with quanxi exchange", Journal of Managerial Psychology, Vol. 31, No. 1, pp. 127-140.

Judge, T. A. and Piccolo, R. F. (2004), "Transformational and transactional leadership: a meta-analytic test of their relative validity", Journal of Applied Psychology, Vol. 89, No. 5, pp. 755-768.

Kelloway, E. K., Barling, J. and Helleur, J. (2000), "Enhancing transformational leadership: the roles of training and feedback", Leadership \& Organization Development Journal, Vol. 21, No. 3, pp. 145-149.

Kristof-Brown, A (1996), "Person-organization fit: An integrative review of its conceptualizations, measurement, and implications", Personnel Psychology, Vol. 49, pp. 1-49.

Kristof-Brown, A., Zimmerman, R. D. and Johnson, E. C. (2005), “Consequences of individuals' fit at work: A meta-analysis of person-job, person-organization, 
person-group, and person-supervisor fit", Personnel Psychology, Vol. 58, pp. 281-342.

Laschinger, S. and Finegan, J. (2005), "Empowering nurses for work engagement and health in hospital settings", Journal of Nursing Administration, Vol. 35, No. 10, pp. 439-449.

Lauver, K.J., and Kristof-Brown, A. (2001), “Distinguishing between employees' perceptions of person-job and person-organization fit", Journal of Vocational Behavior, Vol. 59, pp. 454-470.

Lewin, K. (1952), Field Theory in Social Science: Selected Theoretical Papers. London: Tavistock Publications.

Li, C., Zhao, H. and Begley, T. M. (2015), “Transformational leadership dimensions and employee creativity in China: A cross-level analysis", Journal of Business Research, Vol. 68, No. 6, pp. 1149-1156.

Luthans, F., Norman, S. M., Avolio, B. J. and Avey, J. B. (2008), “The mediating role of psychological capital in the supportive organizational climate - employee performance relationship", Journal of Organizational Behavior, Vol. 29, No. 2, pp. 219-238.

Macey, W. H., Schneider, B., Barbera, K. and Young, S. A. (2009), Employee Engagement: Tools for Analysis, Practice, and Competitive Advantage. London: Blackwell.

Maslach, C. (2003), "Job burnout new directions in research and intervention", Current Directions in Psychological Science, Vol. 12, No. 5, pp. 189-192.

Maslach, C. and Leiter, M. P. (1997), The Truth About Burnout. San Francisco: Jossey-Bass.

Matzler, K., Bauer, F. A. and Mooradian, T. A. (2015), "Self-esteem and transformational leadership", Journal of Managerial Psychology, Vol. 30 No. 7 , pp. $815-831$.

May, D. R., Gilson, R. L. and Harter, L. M. (2004), “The psychological conditions of meaningfulness, safety and availability and the engagement of the human spirit at work", Journal of Occupational and Organizational Psychology, Vol. 77, No. 1, pp. 11-37. 
Michaelis, B., Stegmaier, R. and Sonntag, K. (2010), "Shedding light on employees' innovation implementation behavior: The role of transformational leadership, commitment to change, and climate for initiative", Journal of Managerial Psychology, Vol. 25 No. 4, pp.408 - 429.

Nguyen, T. T., Mia, L., Winata, L. and Chong, V. K. (2017), "Effect of transformational-leadership style and management control system on managerial performance”, Journal of Business Research, Vol. 70, pp. 202213.

Pheng, L. S. and Yuquan, S. (2002), “An exploratory study of Hofstede's crosscultural dimensions in construction projects", Management Decision, Vol. 40, No. 1, pp. 7-16.

Piccolo, R. F. and Colquitt, J. A. (2006), "Transformational leadership and job behaviors: The mediating role of core job characteristics", Academy of Management Journal, Vol. 49, No. 2, pp. 327-340.

Podsakoff, P. M., Mackenzie, S. B., Lee, J. \& Podsakoff, N. P. (2003) “Common method biases in behavioral research: a critical review of the literature and recommendation remedies", Journal of Applied Psychology, Vol. 88: 879-903.

Podsakoff, P. M., MacKenzie, S. B. \& Podsakoff, N. P. (2012), "Sources of method bias in social science research and recommendations on how to control it", Annual Review of Psychology, Vol. 63: 539-569.

Podsakoff, P. M. and Organ, D. W. (1986) Self-reports in organizational research: Problems and prospects. Journal of Management, Vol. 12, No. 4, pp. 531-544.

Purcell, J. (1999), “Best practice and best fit: chimera or cul-de-sac?", Human Resource Management Journal, Vol. 9, No. 3, pp. 26-41.

Purvanova, R. K., Bono, J. E. and Dzieweczynski, J. (2006), “Transformational leadership , job characteristics , and organizational citizenship performance", Human Performance, Vol. 19, No. 1, pp. 1-22.

Raja, M. W. (2012), "Does transformational leadership leads to higher employee work engagement . A study of Pakistani service sector firms", International 
Journal of Academic Research in Business and Social Sciences, Vol. 2, No. 1, pp. 160-166.

Resick, C. J., Baltes, B. B. and Shantz, C. W. (2007), "Person-organization fit and work-related attitudes and decisions: examining interactive effects with job fit and conscientiousness", Journal of Applied Psychology, Vol. 92, No. 5, pp. 1446-1455.

Saks, A. M. and Ashforth, B. E. (2002), "Is job search related to employment quality? It all depends on the fit", Journal of Applied Psychology, Vol. 87, No. 4, pp. 646-654.

Salanova, M., Lorente, L., Chambel, M. J. and Martínez, I. M. (2011), "Linking transformational leadership to nurses' extra-role performance: the mediating role of self-efficacy and work engagement", Journal of advanced nursing, Vol. 67, No. 10, pp. 2256-2266.

Schaufeli, W. B., Salanova, M., Bakker, A. B. and Alez-rom, V. G. (2002), "The measurement of engagement and burnout: A two sample confirmatory factor analytic approach", Journal of Happiness Studies, Vol. 3, No. 1, pp. 71-92.

Shamir, B., House, R. J. and Arthur, M. B. (1993), “The motivational effects of charismatic leadership: A self-concept based theory", Organization Science, Vol. 4, No. 4, pp. 577-594.

Simmering, M. J., Fuller, C. M., Richardson, H. A., Ocal, Y. and Atinc, G. M. (2016), "Marker variance choice, reporting, and interpretation in the detection of common method variance: A review and demonstration", Organizational Research Methods, Vol. 18, No. 3, pp. 473-511.

Song, J. H., Kolb, J. A., Lee, U. H. and Kim, H. K. (2012), “Role of transformational leadership in effective organizational knowledge creation practices : Mediating effects of employees' work engagement", Human Resource Development Quarterly, Vol. 23, No. 1, pp. 65-101.

Sosik, J. J., Godshalk, V. M. and Yammarino, F. J. (2004) Transformational leadership, learning goal orientation, and expectations for career success in mentor-protégé relationships: A multiple levels of analysis perspective. The Leadership Quarterly, 15(2), pp. 241-261. 
Sperber, A. D., Devellis, R. R., \& Boehlecke, B. 1994. “Cross-cultural translation: methodology and validation", Journal of Cross-Cultural Psychology, Vol. 25, pp. 501-524.

Spreitzer, G. M., Perttula, K. H. \& Xin, K. (2005), “Traditionality matters: an examination of the effectiveness of transformational leadership in the United States and Taiwan”, Journal of Organizational Behavior, Vol. 26, No. 3, pp. 205-227.

Stevens, J. P. (2009), Applied Multivariate Statistics for the Social Sciences, New York: Routledge.

Tims, M., Bakker, A. B. and Xanthopoulou, D. (2011), "Do transformational leaders enhance their followers' daily work engagement?", The Leadership Quarterly, Vol. 22, NMo. 1, pp. 121-131.

Walumbwa, F. O., Avolio, B. J. and Zhu, W. (2008), "How transformational leadership weaves its influence on individual job performance: The role of identification and efficacy beliefs", Personnel Psychology, Vol. 61, No. 4, pp. 793-825.

Walumbwa, F. O. and Lawler, J. J. (2003), "Building effective organizations: transformational leadership, collectivist orientation, work-related attitudes and withdrawal behaviours in three emerging economies", The International Journal of Human Resource Management, Vol. 14, No. 7, pp. 1083-1101.

Wang, L., Hinrichs, K. T., Prieto, L. \& Howell, J. P. (2013), "Five dimensions of organizational citizenship behavior: Comparing antecedents and levels of engagement in China and the US", Asia Pacific Journal of Management, Vol. 30, No. 1, pp. 115-147.

Wang, H., Law, K. S., Hackett, R. D., Wang, D., Chen, Z. X., Wang, H. U. I., Law, K. S., Hackett, R. D., Wang, D. and Chen, Z. X. (2005), "Leader-member exchange as a mediator of the relationship between transformational leadership and followers' performance and organizational citizenship behavior", Academy of Management Journal, Vol. 48, No. 3, pp. 420-432. 
Warr, P. and Inceoglu, I. (2012), “Job engagement, job satisfaction, and contrasting associations with person-job fit", Journal of Occupational Health Psychology, Vol. 17, No. 2, pp. 129-138.

Xanthopoulou, D., Bakker, A. B., Demerouti, E. and Schaufeli, W. B. (2007), "The role of personal resources in the job demands-resources model", International Journal of Stress Management, Vol. 14, No. 2, pp. 121-141.

Yukl, G. (2010) Leadership in organizations, 7th ed. Englewood Cliffs, NJ: Prentice Hall.

Zacher, H. and Jimmieson, N. (2013), "Leader - follower interactions: relations with OCB and sales productivity", Journal of Managerial Psychology, Vol. 28 No. 1, pp. $92-106$

Zhu, W., Avolio, B. J. and Walumbwa, F. O. (2009), "Moderating role of follower characteristics with transformational leadership and follower work engagement", Group \& Organization Management, Vol. 34, No. 5, pp. 590619. 


\begin{tabular}{lllllllll}
\hline Variables & 1 & 2 & 3 & 4 & 5 & 6 & 7 & 8 \\
\hline 1. Gender & --- & $-.15^{* *}$ & .03 & $.27^{* *}$ & $-.14^{* *}$ & -.00 & -.09 & -.04 \\
2. Age & & --- & $.14^{* *}$ & $-.43^{* *}$ & $.96^{* *}$ & .01 & $.09^{*}$ & $.10^{* *}$ \\
3. Educational level & & & --- & .07 & $.19^{* *}$ & -.07 & -.05 & -.06 \\
4. Position & & & & --- & $-.40^{* *}$ & $-.11^{* *}$ & $-.19^{* *}$ & $-.15^{* *}$ \\
5. Working experience & & & & & --- & .01 & $.09^{*}$ & $.12^{* *}$ \\
6. Transformational leadership & & & & & & $\mathbf{( . 9 7 )}$ & $.64^{* *}$ & $.52^{* *}$ \\
7. Work engagement & & & & & & $\mathbf{( . 9 6 )}$ & $.67^{* *}$ \\
8. Personal-job fit & & & & & & & $\mathbf{( . 9 0 )}$ \\
& & & & & & & & \\
$\quad$ Mean & & & & & & & & \\
$\quad$ Standard deviation & .50 & 8.91 & .83 & .91 & 9.51 & .93 & .92 & .91 \\
\hline
\end{tabular}


Table 2. Fit indices for confirmatory measurement and structural models

\begin{tabular}{|c|c|c|c|c|c|c|}
\hline Model & $\chi^{2}$ & df & CFI & TLI & RMSEA & 90\% RMSEA CI \\
\hline 5-factor transformational leadership & 400.87 & 165 & .97 & .97 & .045 & $(.040-.051)$ \\
\hline 3-factor work engagement & 150.96 & 24 & .98 & .97 & .087 & $(.074-.101)$ \\
\hline 2-factor person-job fit & 15.50 & 8 & .99 & .99 & .037 & $(.000-.064)$ \\
\hline 3-Factor full model (transformational leadership, & 1299.32 & 650 & .96 & .96 & .038 & $(.035-.041)$ \\
\hline
\end{tabular}


Figure 1. Results for the structural model

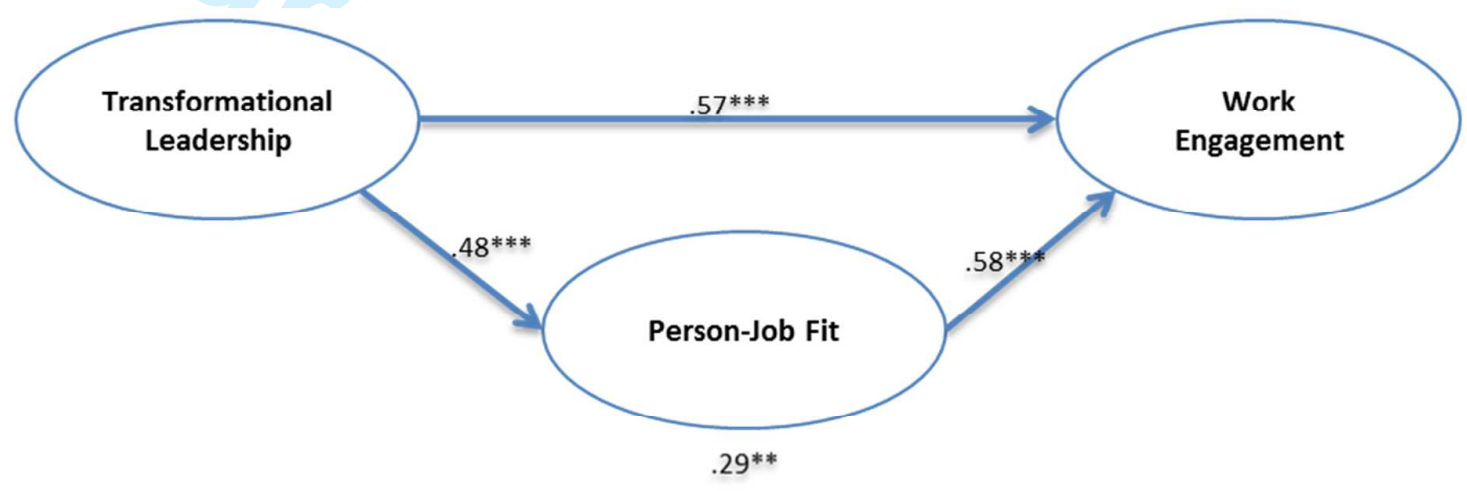

